\title{
Purpose, Human Sociality and Nature in Akiwowo's Sociology of Knowledge: A Realist Interpretation.
}

\author{
Adeolu Ademoyo \\ Africana Studies And Research Center, Cornell University, USA. \\ Email:aaa54@cornell.edu
}

\begin{abstract}
:
This paper advances the view that there is an ontological commitment in Akiwowo's sociology of knowledge which offers an exposition of his thought on purpose, human sociality, nature and society. The paper defends a realist interpretation of this ontology. It argues that a realist interpretation of Akiwowo's account of human sociality, nature and society shows two major conclusions. One, social actions in society are human actions. Human actions are not isolated atoms. Therefore social actions are linked by the agency and, subjectivity of the human which is imbued with values and her/his capacity of sociality. Two, a condition for the continuous existence of a society is that such society has goals. The evidence for this is simple: we see it. This view of society differs from the traditional view of purposiveness in society. The paper suggests that these two conclusions show Akiwowo's theoretical distance from positivism. This rejection of positivism moves him closer to a natural law position.
\end{abstract}

\section{Introduction}

Akiwowo offers a view of sociology of knowledge which defends a perspective of man and society from a non-positivistic standpoint. Akiwowo's non-positivistic standpoint uses conceptual resources from a concrete experience-an African society. His arguments have invited useful responses from other scholars. Given that Akiwowo's account has a fairly wide scope, I will like to be specific about the scope of this paper. First, my concern is Akiwowo's arguments about the purposive nature of the sociality of man and co-existence. Second, I am interested in his arguments about death, incarnation and reincarnation of society. By death, incarnation and reincarnation of society, I take Akiwowo to be engaging an important sociological and philosophical question about the sustainability of society and how society invent and reinvent itself. Akiwowo's suggestion about death, incarnation and reincarnation of society can be extended to civilizations-in other 
words how civilizations die and reinvent themselves. Finally, I hope to explain these two concerns from a realist ontological standpoint. My explanation hopefully addresses some of the challenges advanced by Lawuyi and Taiwo (1990) on Akiwowo's sociology of knowledge.

\section{Ontology And Explanations}

Someone's ontology often consciously or unconsciously structures one's explanations. For example what one takes to be the nature of the world will structure how one conceives of nature itself, the human person; whether or not each constituent of nature such as human person has some powers, what the nature of such power is, and towards what goal such powers are directed by the human being. The downside of someone's conscious or unconscious ontological choice however is that one's explanation may not be able to get outside such ontological standpoint regardless of how sound and plausible such explanations are. This notwithstanding, the exposition of one's ontological standpoint adds some coherence to an explanation. Therefore, a better understanding of an explanation or argument may require that we examine the possible underlining ontological assumptions in the explanation. This is the case with the substantive materials and data (the asuwada African oral poetry) which form the basis of Akiwowo's sociology of knowledge. Akiwowo has a view of human sociality and a view of continuous sustainability of society. He puts the latter as the reincarnate potential of society. The two views are derived from the asuwada oral poetry, an African oral poetry.

Lawuyi and Taiwo identify three senses of asuwada in Akiwowo's account of human sociality as follows:

a. asuwada as a story of creation, about origins, about how something came about on Earth. In this sense, asuwa is a principle of things in virtue of which different things assume different forms. (Lawuyi \& Taiwo, 1990).

b. Asuwada as an expression of the nature of human beings who possess the capacity to form purposive and purposeful bonds and live together as one entity. This is asuwada as a state of being in potentia. (Lawuyi \& Taiwo: 1990).

c. Asuwada as a quality of sociality which involves co-existence and coming together for a common end.

While Lawuyi and Taiwo correctly draw attention to the difference between the first and second conceptions on one hand and the similarity between the second and third conceptions on the other hand in Akiwowo's account of sociality, however, the problem is their charge of fuzziness in Akiwowo's explanation. According to Lawuyi and Taiwo, the fuzziness arises from the third sense of asuwada. Lawuyi and Taiwo suggest that the 
third sense of asuwada in Akiwowo's account makes a case that society has a purpose which it seeks to attain. This case is made because in the third sense, according to Lawuyi and Taiwo, Akiwowo assumes that each time humans co exist in society, they necessarily co-exist for a purpose. Since co-existence is taken to imply society, on this view it means that society is taken by Akiwowo to have a purpose. Having ascribed the view that society has a purpose to Akiwowo in virtue of the third sense of asuwada in Akiwowo's explanation, Lawuyi and Taiwo suggest that this view is implausible given that sociological theory has shown the error in the assumption that society has a purpose. (Lawuyi and Taiwo, 1990: 60). The two make specific reference to Popper's critique of the view that society has a purpose. They assert that Akiwowo must defeat Popper's standpoint on this before his account can stand. It is not obvious however if Lawuyi and Taiwo's correct challenge to Akiwowo's total sociological project also take account of the possibility of more than one explanation of purposiveness of society in their specific critique of this aspect of Akiwowo's views.

A different reading of Akiwowo helps to explain the difficulties that Lawuyi and Taiwo on one hand and Jimi Adesina on the other (Adesina, 2002) point to. This sort of reading does two things. It identifies and separates the view that a human has the quality of sociality and the view of society upon which Akiwowo's sociological thought is based. I suspect that Lawuyi and Taiwo's critique of Akiwowo on a different kind of purposiveness in society and Adesina's tacit agreement of this critique do not recognize this separation or if they recognize it, they do not think the separation helps an understanding of Akiwowo on what I suggest is Akiwowo's view of a different kind of purposivieness in society. Given this possibility Lawuyi and Taiwo take a feature of Akiwowo's view of society which is that society is goal seeking to mean that Akiwowo derives and infers this from his sociological account of the sociality of human. While it is true that Akiwowo holds the view that society is goal seeking, it is not obvious that he derives this view primarily from his standpoint on the sociality of a human person. Furthermore, neither does he defend this view from that standpoint. I wish to point to a different direction upon which Akiwowo bases his view that society is goal seeking and hence purposive. In doing this, I hope to separate the two views and show how they differently help explain the ontological commitments inherent in Akiwowo's sociological thought. The second help this reading offers is that it shows the ontological commitments in Akiwowo's thought-a commitment which offers a different reading of the view that a human has the quality of sociality and the view of that society has the possibility to continuously reinvent self, the re-inventive possibility inherent in societywhat Akiwowo calls the reincarnating capacity of society. Both views are explicable on the strength of realist ontology. And given Akiwowo's critical distance from positivism, I will point to the direction that his view of society has an ethical component that suggests an unstated natural law stand point. A crucial point however is that these accounts come from indigenously sourced sociological materials. The more important task however is 
to theorize them and make them relevant to the solutions of some of Africa's more contemporary problems which in the present period are self inflicted.

This way of looking at Akiwowo is relevant precisely because -as Akiwowo himself suggests- much of the preceding sociological reasoning rests on a philosophical foundation. And that foundation has an ontology which is positivist ontology. Therefore if -as I hope to show presently - Akiwowo's accounts of the sociality of human and the sustainability of society rest on a particular ontology which I suggest is quasi realist ontology, then it is more productive to first read his thought on this basis. There is no doubt that a critique of Akiwowo's thought from a different ontological standpoint is useful, it is however equally useful to recognize this different ontological standpoint when this is being done.

\section{Power, Purpose And Human Sociality}

I take my reading of realist ontology from Oladipo Fashina (Fashina, 1981). My reading of Fashina which is relevant for my exposition of Akiwowo is that Fashina makes a defense of a thought which is often used to define wrongly the totality of African thought. Fashina engages a neo-Kantian criticism of mythical consciousness in his account of realist ontology. Cassirer, a neo-Kantian has argued that mythical consciousness is false because it shows what the neo-Kantian calls "un-discriminatory perception of the world”. Cassirer maintains this position because in Cassirer's view mythical thought belongs to the species of non-empirical thought. While empirical thought is dialectical, mythical thought on this view according to Cassirer is not dialectical (Fashina, 1981). In his objection to Cassirer, and his explanation of mythical consciousness on the strength of realist ontology, Fashina offers the following understanding of the ontology. What does realist ontology look like? According to Fashina:

It asserts that there are mind -independent causal mechanisms in the world; these take their explanation from the "nature" of things in the physical world (Fashina, 1981).

Fashina goes further:

Individual things also have powers: powers are what things have in virtue of their inner constitution or structure; In the realist view, then, all inhabitants of the natural world are powerful particulars. As powerful particulars they are causal agents; this means that individuals behave the way they do because they have powers. Because the powers of a thing are determined by its nature, what a thing can make happen and what it can undergo are prescribed by its inner constitution (Fashina, 1981: 40-41). 
Although Lawuyi and Taiwo do not claim to be neo-Kantians in their critique of Akiwowo, their critique that Akiwowo engages in fuzzy logic and that Akiwowo's thought on human sociality and purposiveness in society, echoes Cassirer's neoKantian critique of mythical consciousness as a form of consciousness that engages in un-discriminatory perception. Let us examine Akiwowo's account within the larger frame of realist ontology to see the point at which charges of fuzziness in thought or un-discriminatory perception becomes problematic. Akiwowo's notion of sociality of human nature is derived from an Orunmilaist conception of human and society (Akiwowo, 1983). On this conception, sociality is a quality which a human has. This view can be further understood in the context of a realist ontology which posits the view according to Fashina that inhabitants of the natural world are powerful particulars. The power is what makes each particular individual what he/she/it is. The quality of sociality in this context should be understood as a power of an individual human being -a power or quality that makes him or her what she or he is. Though neither Akiwowo's view on sociality as a quality which a human has nor Fashina's standpoint on a realist ontology substitutes power for quality and vice versa in their explanations, however a power in this sense can be understood as a capacity just as quality can also be taken to mean a capacity which a human is capable of exercising and which he or she exercises as an essence that identifies him or her. This explanation may not free Akiwowo from the charge of fuzziness yet. This is because what Lawuyi and Taiwo are arguing against is the inference which they claim Akiwowo draws between the view that human has a quality of sociality which is exercised and causes co-existence and the claim based on this view that society has a purpose which it seeks to attain. In other words, Lawuyi and Taiwo believe that Akiwowo infers the claim that society has a purpose from the sociality of a human person without showing the basis of such inference. Lawuyi and Taiwo's critical reading of Akiwowo seems to have proceeded from two premises. One is the Popperian critique of the view that society has a purpose it seeks to achieve. The second premise is a logical error of allocating to society a feature which individual members of society are presumed to have. Lawuyi and Taiwo suggest that conceptually Akiwowo commits the latter error and that substantively he will need to respond to the Popperian critique that a society has a purpose.

A systematic explanation of Akiwowo's view that a human has the quality of sociality which makes humans co-exist, and his view of society may help throw more light on the difficulties that some critics have observed with respect to Akiwowo's sociology of knowledge. I take the view on human sociality first. From the realist ontological view as stated earlier, we know that the realist holds a view of powers and causes in the natural world that shows that events happen and things exist in a connected manner. This position calls to question a rival view point that the constitution of the world is such that events happen and things exist in a disconnected atomized manner. For example such atomized manner of looking at the world creates a dichotomy between 
facts and value, self and the other etc. Following this thread of claim, the argument in the latter viewpoint is often extended in the claim that there is no analytic justification why we should not have a dichotomy between fact and value. In other words relations and especially causal relations must be conceptually and analytically specified otherwise such relations are implausible. And where there is a merging of the dichotomies such as fact and value, an independent reason is often and must be sought a posteriori on this positivistic view to show such merging. The latter view point defines some positivistic and neo-positivistic thinking. In rejecting this way of looking at the world, the realist would suggest that the view that things just happen and are not connected is a myth. This is the realist ontology of powers. And on our knowledge of causes, the realist would argue that we have the knowledge of causes of things when we "have discovered the internal mechanisms that generate them" (Fashina, 1981:41). In other words inhabitants of the natural world have causal powers. And since such causal powers are the inner constitution of each inhabitant, we can apply this reasoning to Akiwowo's exposition. In doing this the quality of sociality which Akiwowo suggests that humans have should thus be understood as part of the powers that define the inner constitution of the human being.

A relevant question is: what explanation does Akiwowo offer to show that sociality is a human quality which everyone has such that we are able to interpret such quality on the realist conception of power? Akiwowo's explanation of his standpoint is episodic. Though Akiwowo does not advance a step by step justification of each of his claims, his method notwithstanding, he offers an explanation of his claims about the quality of human sociality. He also offers an explanation of the different view he holds about the goal seeking nature of society. For example on the issue of sociality as a capacity a human has, Akiwowo advances a presupposition about existence which he calls iwa susu or bunched existence. Iwa susu as bunched existence is derived from the sociological materials Akiwowo is engaging. Given the positivistic metaphysics which Akiwowo's sociology of knowledge is arguing against, I suggest that bunched existence in Akiwowo's thought is a presupposition from which the view that sociality is a human capacity is derived. In contrast to a sociological explanation of human and his or her action in society, bunched existence, iwa susu is a metaphysical view that provides a background to some of Akiwowo's deductions. ${ }^{1}$

Iwa susu, ( an explanatory model which offers the metaphysical background to Akiwowo's assertion that human has the capacity for sociality) which is understood as bunched existence is a metaphysics of existence and the intuition in it takes us back to the ultimate presupposition or the ontology inherent in any explanation offered by

1 Though Lawuyi and Taiwo have pointed out the equivocation in Akiwowo's thought on the concept of (i.e. iwa-as a moral concept and as a metaphysical concept), the equivocation notwithstanding, there is a coherence in Akiwowo's deductions about man and society and his metaphysical standpoint on existence if Iwa as a metaphysical concept is privileged. Obviously, the intuitions in iwa as a moral concept and iwa as a metaphysical concept are different. Iwa as a metaphysical concept does a better job of explaining Akiwowo's sociology of man and society. 
scholars. Akiwowo seems to have derived a priori human sociality from bunched existence as an ultimate presupposition which underscores his conclusions on human sociality. (Akiwowo, 1986:348). Bunched existence is a pre-reflective or pre-figured mode of human existence. ${ }^{2}$ Bunched existence is a human state before existence was reflected upon, chopped and atomized by reason. On this view, Akiwowo's account of sociality as a capacity a human has shows that a human being is a powerful particular, who has the causal power for co-existence with other human beings in a social process which is capable of responding to the alienation of self from the other. This is precisely because an individual person who has this power is a product of persons who, metaphysically speaking, were in the pre-reflective mode of existence as bunched existence prior to being reflected upon, chopped and atomized by reason. To defeat the view that human being has this causal power of sociality, which is derived from pre-reflective existence as bunched existence, one must first defeat a pre-reflective state of existence as bunched existence. However, given that iwa susu, bunched existence is a rival metaphysics of existence to a Hobessian view of state of nature, arguments in defense of one metaphysical view often lead to arguments in support of the other, even though conceptually, there could be grey areas between iwa susu, bunched existence, and a Hobessian state of nature. Given that iwa susu or bunched existence is an original state of connected existence, Akiwowo's thinking that a human has the causal power of sociality which disposes human beings to co-exist is therefore plausible on the view that such power is derived from an original state of bunched existence. Thus the Akiwowo view that sociality is a capacity which is a power or quality humans have and which disposes humans to co-exist is further explicable on the realist claim about the existence of causal mechanisms in the world. On this view, a realist answer to the question: what causes social existence, will be that this is caused by the nature of human being which has the power or quality of sociality. This sort of answer clarifies the causal explanation between human sociality and human co-existence in Akiwowo's sociology of knowledge of man. The upshot of this is that Akiwowo seems to believe that a metaphysics of existence such as his view of bunched existence, or iwa susu, is also an explanation of the powers or quality that particulars who presumably are pre figured by such state have. In other words, Akiwowo is implying that ontology explains a sociological account of actions of a social unit such as a human or that an ontological answer justifies and explains a sociological account. This is the way to understand bunched existence, iwa susu, which is an ontology, a metaphysics of existence (which I understand as a rival metaphysics to a Hobessian metaphysics of atomized human relations of existence in a state of nature), and the view of sociology of man which

2 On a similar issue but with a different objective, Merleau Ponty maintains similar views about social relations when he traces the origin of alienation in a child's relation to the other to the role of reason. In Ponty's critique of classical psychology Ponty shows how classical psychology falls into the trap of alienation and the role theoretical reason plays in this. Akiwowo's bunched existence and Ponty's critique of classical psychology seems to share a view of the source of alienation in society 
asserts that human has the quality of sociality.

\section{Power, Purposiveness and Co-existence}

The challenge before Akiwowo's account however is to show that the relationship between human sociality and co-existence is purposive. One way to respond to this challenge is to ask what sort of relationship exists between sociality as a human capacity and co-existence of humans who have such capacity. If as it is suggested in this essay, the relationship between human sociality and co-existence can be understood in causal terms, then the challenge turns on whether causal mechanisms in general are purposive. The answer to this question rests on the type of causal mechanism at work. And the type of causal mechanism at work depends on the forces involved in such mechanisms. Are such forces human or physical? For example a cause and effect relationship between the light and the striking of a match box with a match stick is different from the type of causal mechanism between a human and his/her capacity of sociality on one hand and co-existence on the other. While the effect in the former can be said to be without purpose, that the effect of causal mechanism in the latter is without purpose is counter intuitive. This is because while a person in the latter is animate, a match stick in the former is not. Additionally, a capacity of sociality which is the causal factor is not dormant nor does it reside in human for its sake otherwise it ceases to be what it is. If this analogy is granted, then the import of this is that we meet the purposive nature of the sociality of human when we are called upon to explain the nature of that sociality and the internal mechanisms or causes ( a la a realist understanding of causes) that generate certain human actions and certain societal actions. The purposive nature of the capacity of sociality which a human has is therefore explicable on the view that human and social actions cannot be an arbitrary occurrence the way causal mechanism in inanimate objects can be arbitrary.

The upshot of this is that if one is asked the question: why do we co-exist? There would be different answers-both plausible and implausible. On the view that things in the world are constituted in an unconnected manner, an obviously Humean view, as Fashina rightly points out, the Humean answer would be that "we simply co-exist". This answer would imply that anything can follow from anything. But this view is not only counter intuitive; it is a view more akin to myth than science (Fashina, 1981:42). This is because nothing just exists. It is true that we may claim that in the interim we do not have specific explanation for the existence of a thing, but it is strange to even science to claim that something simply exists. Therefore, on the strength of a Humean and a positivist explanation, since anything can come from anything, co-existence would have to be founded on a factor independent of our nature and power. A further pressing of the argument on a Humean term returns us to the Hobessian state of nature -a state of disconnection-where independent reasons 
(independent of the values taken to be inherent in human nature and its sociality) have to be found to explain the coming together of humans. But our conceptual resources are not limited to a Humean answer or ontology and neither is our conceptual resources limited to a positivist extension of such Humean ontology.

Based on Akiwowo's sociology of knowledge, a different answer is possible on the strength of a realist ontology of powers and natures. And this is that our disposition to co-exist flows from the nature and power of the human being. Since we as humans do not exist outside the natural world, and given that we are part of the powerful particulars in the world which the realist posits, and, which is also posited in Akiwowo's synthesis of the Orunmila perspective on man and society, it also means that things in the natural world exist in a causal relation to one another. This involves the view that things do not just happen arbitrarily. The denial of arbitrariness (a denial based on the ontology of powers and natures) between the sociality of the human being and co-existence as articulated by Akiwowo creates a distance in theory and practice from positivism which is committed to a dualism that runs through its explanations. The chopping and atomization of human nature which positivists and neo positivists are committed to is challenged by a more holistic view of human nature inherent in Akiwowo's sociology of knowledge.

An objection to the conceptual move to use the ontology of powers and natures to explain Akiwowo's sociology of knowledge on the nature of man and society may be that if such conceptual move is based on the realist account of the nature of cause as articulated by Fashina, then the move establishes nothing different from a Humean, Hobbesian or positivist explanation of co-existence which Akiwowo by implication endeavors to distance himself from theoretically. In other words, the objection is that neither Hobbes nor the positivist denies that human beings co-exist, and that humans cause the co-existence. If this is the case, then Akiwowo's explanatory model does not establish anything. My response is that the objection does not recognize that Akiwowo's position takes a different view of human nature such that we do not look outside this nature to explain human co-existence. In other words sociality as a human quality and power logically generates co-existence because sociality as a quality is not a mere formal quality or power devoid of intuitions. The quality of sociality is both a mode and an intuition. In other words, sociality is not a mere formal quality which does not have substance to it. Here, on Akiwowo sociology, we have a unity of the mode and the substance of sociality as a power or quality which a human person has. We do not have a mechanical division between substance and the mode which commits us to a search for independent reasons for co-existence as we have it in a Hobbes's state of nature. That sociality is a quality imbued with intuitions is what Akiwowo means when he asserts that humans are vessels of values (Akiwowo, 1983:11). The values should be taken as the intuitions embedded in sociality. This sort of unity of mode and substance inherent in sociality as a human capacity makes Akiwowo's thought to gravitate towards a natural 
law position. This is what he seems to be resolving indirectly in his thought and it forms part of his theoretical distance from positivism. Thus if co-existence is taken as one of the social constants in the world then on this view it is not an arbitrary occurrence. It is caused by sociality as a capacity of human-a sociality that has content to it. The nonearbitrary nature of co-existence should thus be understood to mean that the sociality of human being is purposive i.e. directed at the co-existence of humans on the basis of values inherent in that capacity. And this is consistent with Akiwowo's sociological thought on human sociality which disposes us to co-exist.

\section{Purposiveness: Agency And Co-existence}

The purposive nature of the causal mechanism involved in human actions seems clearer on a view held by Akiwowo (Akiwowo, 1983:11). The view that humans are vessels of values adds the factor of agency, subjectivity and content to the capacity of sociality. This is because the goal directed nature of human sociality is not devoid of values. On this view values mediate co-existence. Therefore, from the standpoint of a realist view of cause, the purposiveness in human actions distinguishes the causal mechanism in human actions from the causal mechanism in inanimate objects.

I conclude this section of the essay in three parts. Bearing in mind Lawuyi and Taiwo's criticism, I point to the distinction Akiwowo draws, albeit very briefly between coexistence and co-existence for a purpose. I offer a view of purposiveness in co-existence which defends Akiwowo's sociology of knowledge of man and society. I explain Akiwowo's claim about the goal seeking nature of society.

Though Akiwowo claims that society is goal seeking, he seems to have maintained this position on an explanation other than the one he offers on human sociality. This is because he draws a distinction between the fact that humans do co-exist, and, the act of co-existing for a common end. He asserts that

\footnotetext{
By sociality we mean the quality of being able to live and grow in communities; the quality or fact of being able to establish companionship and mutual converse, in the Orunmilaist perspective is simply the quality of being able to suwada (come together for a common end; to co-exist. The perspective clearly distinguishes between asuwa (co-existence), and asuwada (the fact of being together for a purpose). (mine emphasis)(Akiwowo, 1983:16).
}

This assertion is an awareness by Akiwowo that the two are different. But Lawuyi and Taiwo have argued that Akiwowo seems to believe that each time humans co-exist, they co-exist for a purpose. In showing the problems in this view, Lawuyi and Taiwo give the analogy of the bus and the commuters. The bus analogy illustrates the fact that the act of co-existing in a bus by commuters on a ride does not mean that they co-exist for a common end. However, a closer look at the analogy shows that it seems to be more 
relevant to a different issue about our individuality. And this is not a controversial issue. On the contrary, Akiwowo is engaging a different issue. The issue is an ontological position that seems to have atomized our individuality-an individuality which the bus analogy correctly shows but whose atomization it cannot address. This is because the way our individuality is accounted for may unintentionally legitimize this atomization and solipsism as inevitable states without paying attention to the possible reason for this wrongly presumed inevitability. ${ }^{3}$ The bus analogy is unable to show this. And this, presumably, is unintended by Lawuyi and Taiwo. This is why Akiwowo's explanations are more sophisticated than they appear. It is true that when I sit in the bus on a ride, I do have my individuality and specific, private and personal individual ends-i.e. my destination, my feelings, my world etc. But these specific, private and personal contents of my individuality are connected to those of others in the bus and outside the bus by the very nature of the capacity of sociality which Akiwowo claims that I as a human have. To resist this is to claim that the commuter is no different from a luggage in the bus which has a destination too. For example if we accept Lawuyi and Taiwo's bus analogy this implies that there is no difference between a Segun and a Kofi who co-exist in a bus ride on one hand and the co-existing of a Segun and a luggage in the bus on the other. Lawuyi and Taiwo may rebut and ask that I should be concrete and name the common end in the co-existence of Segun and Kofi in the bus. Even though Akiwowo's explanation is an argument against the formalism of the social nature of each human agency and co-existence, one can answer Lawuyi and Taiwo's rebuttal that Segun and Kofi's human sociality dispose them to have the safety of the bus as a common end without any prior or written agreement which a formalist and a positivist view of things often require. To be specific by this I mean that as a common end they will not bomb the bus. The bus analogy brings us back to Lawuyi and Taiwo's charge of fuzziness. If I am right, the bus analogy suggests that a requirement that the two commuters have a common purpose in the bus is that such common end or purpose has to be written or said or agreed to by the two commuters. The fuzziness here could be that Akiwowo has not analytically addressed this actuality. This is a literality and formalism which I doubt Lawuyi and Taiwo intended. But if this is insisted upon, then in a more fundamental sense, such insistence brings back the two metaphysics of existence-Hobbes' state of nature and its extension in positivism, and Akiwowo's bunched existence and its possible extension in natural law. This is because it seems that the atomized and chopped nature of human nature and existence commits us to the kind of social relation in the bus analogy-a social relation being resisted by Akiwowo's sociology of man and society.

3 On a different but pertinent case study, Merleau Ponty uses child psychology to show the role reason plays in this process of atomization. He also shows how solipsism emerges from this process. See "The Child's Relations with Others" in Maurice Merleau -Ponty The Primacy of Perception_and "The Intertwining-The Chiasm" and "Pre-Objective Being : The Solipsist World" in Maurice MerleauPonty The Visible and the Invisible. 
Finally, it is true that from a pure analytic standpoint either Segun or Kofi may not have safety as a common end. In other words it could be said that nothing has shown or proved that they do. The problem with this objection is how it is possible in the first place in a fundamental sense to commence a bus ride if nothing has shown or proved that both Segun and Kofi have a common end of safety of the bus. The bus cannot be analytically yanked off the society or other 'buses' in the society. In the same vein while clear conceptual specification is useful, we cannot analytically yank Segun or Kofi off the connection "their bus' has with other buses and still able to make sense of the fact that they are riding a bus and they "hope" to arrive safely. That we do commence a bus ride without such analytic proof is ontologically significant even if analytically and contractually there is no agreement between the two. The societal ramification of this social and public nature of our individuality can be seen in the fact that the bus itself is a layered unit of society which is connected to other buses. To deny this is to be committed to the view that solipsism is an inevitable path for humanity. This philosophical path is what I suspect that Akiwowo's sociology of man and society is challenging and resisting.

Finally, I suggest an explanation of Akiwowo's specific observation of the goal seeking nature of society -an observation which I think is wrongly taken to be the same as the traditional account of purposiveness of society. The view of purposiveness of society in Akiwowo's account is different. Akiwowo's purposiveness in society is radically simple and different from traditional account of purposiveness of society which may be the occasion for totalitarianism in thought and the subject of attack from Popper and others. A thought experiment may help elucidate the position maintained by Akiwowo. And this is it $A$ posteriori we observe that every society tends to want to tenure itself in perpetuity, by constantly reinventing itself. No such self perpetuity follows an unbroken flow. This is what Akiwowo calls reincarnation of society. There must be a reason a society is able to do this. Beside other instruments with which a society may perpetuate itself, a clear articulation of goals is what put these instruments to work. Therefore the reason a society is able to perpetuate itself can only be that it has goals. No self perpetuity happens in a vacuum. Akiwowo's simple experiment is that every society with varying degrees of success actually seeks to reinvent itself; any society which fails to do this dies. In a perceptual manner we can see this. If this is true, there must be a reason that explains this. The reason can only be that society is goal seeking. A society's goals keep such society active and alive socially, economically and politically. Any objection to this explanation must recognize that Akiwowo's account is not prescriptive of goals. If in spite of this critics still feel that Akiwowo's suggestion that society is purposive is implausible then the onus is on such critics to show what explain the tendency of society to self perpetuate, and to show what happens to societies without goals. This specific way of looking at the goal seeking nature of society demands a more engaged look at Akiwowo's sociology of society. 


\section{References}

Adesina, J.O. 2002 "Sociology and Yo rùbá Studies: Epistemic Intervention or Doing Sociology in the "Vernacular'?" African Sociological Review, 6(1).

Akiwowo, A.A. 1983 "Ajobi and Ajogbe; Variations On The Theme of Sociation" Inaugural Lecture Series, Ile Ife, University Press.

Akiwowo, A.A. 1986. "Contributions To The Sociology Of Knowledge From An African Oral Poetry.” International Sociology (1) 4:343-358.

Akiwowo, A.A. 1991. "Responses To Makinde/Lawuyi And Taiwo." International Sociology (6)2 : 243-251.

Akiwowo, A.A. 1999."Indigenous Sociologies: Extending The Scope OfThe Argument." International Sociology (14) 115:114-138.

Fashina, O. 1988. "The Indeterminacy Thesis, Ontological and Linguistic Relativity" Second Order, New Series, An African Journal Of Philosophy Vol 1 No 1.: 63-77. Hobbes, T. 1994 Leviathan Indianapolis: Hacket Publishing Co.

Lawuyi, O.B. \& Taiwo, O.1990. "Towards An African Sociological Tradition: A Rejoinder To Akiwowo And Makinde" International Sociology (5) 1 :57-73. Locke, J. 2003. Two Treatises of Government. Cambridge: Cambridge University Press. Makinde, M.A. 1998. "Asuwada Principle: An Analysis Of Akiwowo's Contributions To The Sociology Of Knowledge From An African Perspective" International Sociology 3 (1): 61-76.

Merleau-Ponty, Maurice 1968, The Visible and the Invisible, Evanston, Northwestern University Press.

Merleau-Ponty, Maurice, 1964, The Primacy of Perception, Evanston, Northwestern University Press.

Payne,M.W.1992."Akiwowo, Orature and Divination: Approaches To The Construction of An Emic Sociological Paradigm of Society” Sociological Analysis 53:2: 175-187. 